\title{
ANALISIS SCREEN OFFENSE TIM BASKET PUTRI UNIVERSITAS NEGERI JAKARTA PADA LIMA BASKETBALL JAKARTA 2019
}

\author{
Lidya ${ }^{1}$, \\ Iman Sulaiman ${ }^{2}$ dan Hendro Wardoyo ${ }^{3}$
}

Fakultas Ilmu Keolahragaan Universitas Negeri Jakarta

$\underline{\text { lidya3816@gmail.com }}{ }^{1}, \underline{\text { isulaiman@unj.ac.id }}{ }^{2}, \underline{\text { hwardoyo@unj.ac.id }^{3}}$

\begin{abstract}
ABSTRAK
Penelitian ini bertujuan untuk mengetahui persentase keberhasilan dan kegagalan screen offense tim basket putri Universitas Negeri Jakarta pada Liga Mahasiswa Basketball Prim-A Greater Jakarta Conference 2019. Metode penelitian ini menggunakan metode deskriptif dengan teknik pengambilan data video yang sudah ada. Populasi pada penelitian ini adalah seluruh pemain tim bola basket putri Universitas Negeri Jakarta pada Liga Mahasiswa Basketball Prim-A Greater Jakarta Conference 2019, sebanyak 12 orang. dan penelitian tersebut digunakan teknik total sampling untuk mendapatkan sampel penelitian yaitu karena pada saat bertanding semua pemain melakukan screen offense maka sampel dalam penelitian ini adalah seluruh pemain basket putri Universitas Negeri Jakarta. Hasil dari analisis screen offense pada video pertandingan Universitas Negeri Jakarta melawan Universitas Tarumanegara diperoleh 15 kali berhasil dan 7 kali gagal, pertandingan Universitas Negeri Jakarta melawan Universitas Esa Unggul 11 kali berhasil dan 13 kali gagal, pertandingan Universitas Negeri Jakarta melawan Universitas President 28 kali berhasil dan 14 kali gagal, pertandingan Universitas Negeri Jakarta melawan Universitas Pelita Harapan 25 kali berhasil dan 29 kali gagal dan pertandingan Universitas Negeri Jakarta melawan Perbanas Institute 20 kali berhasil dan 6 kali gagal, diketahui data dari 5 pertandingan diperoleh 99 kali screen offense berhasil yang menghasilkan persentase $59 \%$ keberhasilan dan 69 kali screen offense gagal yang menghasilkan $41 \%$ kegagalan.
\end{abstract}

Kata Kunci : Analisis, Keberhasilan dan Kegagalan, Screen Offense

\section{ABSTRACT}

This study aims to determine the percentage of successes and failures of screen offense girl basketball team University of Jakarta in the League of Basketball Students Prim-A Greater Jakarta Conference 2019. This research method used descriptive method with existing video data collection techniques. The population in this study were all players of girl basketball team University of Jakarta in the League of Basketball Students Prim-A Greater Jakarta Conference 2019 , as many as 12 people. The study used a total sampling technique to obtain research samples because when competing all players did screen offense, the samples in this study were all girl basketball players at University of Jakarta. The results of the screen offense analysis on the video of the University of Jakarta competed against University of Tarumanegara obtained 15 times succeeded and 7 times failed, University of Jakarta competed against University of Esa Unggul 11 times succeeded and 13 times failed, University of Jakarta competed against University of President 28 times succeeded and 14 times failed, University of Jakarta competed against University of Pelita Harapan 25 times succeeded and 29 times failed and University of Jakarta competed against Perbanas Institute 20 times succeeded and 6 times failed, known data from 5 matches obtained 99 times screen offense successfully, which resulted in a percentage of $59 \%$ success and 69 times screen offense failed which resulted in $41 \%$ failure.

Keywords: Analysis, Success and Failure, Screen Offense 


\section{PENDAHULUAN}

Permainan bola basket adalah permainan yang dimainkan oleh dua tim dengan lima pemain per tim, dimana setiap tim berusaha mendapatkan nilai atau score dengan memasukan bola ke keranjang lawan sebanyak-banyaknya dan mencegah tim lawan melakukan hal yang serupa. Tehnik dasar mencakup footwork (gerakan kaki), shooting (menembak), passing (mengoper) dan catching (menangkap), driblle (menggiring bola), rebound, bergerak dengan bola, bergerak tanpa bola dan bertahan.(Wissel, 2012)

Teknik dasar mencakup footwork (gerakan kaki), passing (menembak), passing (mengoper) dan catching (menangkap), driblle (menggiring bola), rebound, bergerak dengan bola, bergerak tanpa bola dan bertahan. (Rose, 2013)

Setelah melakukan diskusi dengan dosen ahli bola basket dan penelitian kecil yang dilakukan di satu pertandingan menghasilkan hasil diskusi yang menemukan masalah mengenai screen offense, berikut adalah hasil pengamatan kecil yang dilakukan peneliti.

Dari hasil penelitian kecil yang saya lakukan bahwa pada saat pertandingan tim basket putri Universitas Negeri Jakarta melawan Universitas Kesatuan Bogor pada pertandingan Gunadarma Hoop Summit Vol.6 yang diadakan di Universitas Gunadarma Depok, dapat terlihat Universitas Negeri Jakarta melakukan 28 kali screen untuk Offense agar dapat membebaskan pemain satu tim untuk mendapatkan peluang melakukan shooting atau mencetak angka, dari 28 kali percobaan screen tersebut 11 kali berhasil yang artinya melakukan gerakan screen mampu membebaskan teman satu tim mendapat peluang mendapat bola serta mencetak angka dan membuat orang yang menjaga teman satu tim tertahan dengan screen yang dilakukan, serta 17 kali gagal yang artinya gerakan screen yang dilakukan tidak mampu membebaskan teman satu tim dan tetap berada dalam penjagaan lawan.

Tingkat keberhasilan yang dapat dilihat hanya mencapai $39,29 \%$ dan kegagalan mencapai $60,71 \%$, dapat dilihat dari sini antara tingkat keberhasilan dengan kegagalan lebih besar tingkat kegagalan dalam melakukan screen untuk offense.

Dari hasil tersebut dapat dilihat masih banyaknya peluang kegagalan dalam melakukan screen dan karna hal tersebut persentase keberhasilan masih sedikit dalam penggunaan taktik screen dalam offense untuk memecahkan defense lawan.

Maka dari hasil penelitian kecil yang peneliti lakukan pada tim bola basket putri Universitas Negeri Jakarta persentase kegagalan dalam melakukan screen cukup besar salah satunya adalah faktor tidak menyangkutnya lawan pada saat sedang di screen, posisi badan yang melakukan screen kuda-kudanya tidak kuat oleh sebab itu tidak dapat menahan lawan, dan teman yang satu tim yang di screen tidak dapat membawa lawan menyangkut ke arah yang melakukan screen atau shoulder to shoulder oleh sebab teman yang di screen tidak dapat peluang mendapatkan bola untuk finishing atau passing.

Masalah yang ditemukan yang biasa terjadi pada screen offense ialah kegagalan dan keberhasilan screen offense yang dilakukan dalam satu pertandingan, sebab jika keberhasilannya lebih besar dalam melakukan screen offense di satu pertandingan maka besar pula peluang untuk memenangkan pertandingan begitupun sebaliknya jika kegagalan lebih besar dalam melakukan screen offense disatu pertandingan maka besar pula peluang untuk kalah dipertandingan tersebut.

Untuk memenangkan suatu pertandingan bola basket sangat juga dibutuhkan kerjasama dan komunikasi tim yang baik kalau tidak adanya kerjasama dan komunikasi antar pemain di satu tim maka akan terjadi kesalahpahaman di lapangan itulah sebabnya dalam screen offense sangat dibutuhkan kerjasama antar pemain disatu tim untuk dapat membebaskan teman satu tim dari penjagaan agar mendapatkan bola dan mempunyai peluang shooting.

Teknik dasar bola basket ada dribbling, passing dan catching, Shooting, Pivot, Rebound, Footwork, Ball Handling, dan Tuck Position .(Dr Iman Sulaiman, 2019)

a. Teknik menggiring bola (Dribbling) 
Menggiring bola adalah salah satu cara yang diperbolehkan oleh peraturan untuk membawa lari bola ke segala arah. Seorang pemain boleh membawa bola lebih dari satu langkah, asal bola sambil dipantulkan baik dengan berjalan maupun berlari. Cara menggiring bola yang dibenarkan adalah dengan satu tangan (kanan atau kiri). Kegunaan menggiring bola adalah untuk mencari peluang serangan, menerobos pertahanan lawan dan memperlambat tempo permainan.

b. Teknik melempar bola (Passing)

Operan dapat dilakukan dengan cepat, keras, tetapi tidak liar sehingga dapat dikuasai oleh teman yang akan menerimanya. Operan dapat dilakukan secara lunak, tetapi akan tergantung pada situasi keseluruhan, yaitu kedudukan situasi teman, time-ing dan taktik yang digunakan.

c. Teknik menangkap bola (Catching)

Memberikan operan tidaklah semudah yang di duga, karena kerasnya lemparan terlalu rendah atau terlalu tinggi operan akan menyulitkan teman untuk menerima bola. Untuk dapat melakukan operan dengan baik dalam berbagai situasi harus menguasai bermacam-macam teknik dasar melempar dan menangkap bola dengan baik.

d. Teknik menembak bola basket (Shooting)

Keberhasilan suatu regu dalam permainan selalu ditentukan oleh keberhasilan dalam menembak. Dasar-dasar teknik menembak sebenarnya sama dengan teknik lemparan. Jadi jika pemain menguasai teknik mengoper (passing), maka pelaksanaan teknik menembak bagi pemain tersebut akan sangat mudah dan cepat dilakukan. Bentuk-bentuk teknik gerakan menembak dalam permainan bola basket antara lain tembakan satu tangan di atas kepala, tembakan lay-up, menangkap bola dilanjutkan menembak (lay-up), tembakan meloncat dengan dua tangan (jump shoot) dan tembakan kaitan.

e. Teknik dasar bertumpu satu kaki (pivot)

Gerakan pivot ialah berputar ke segala arah dengan bertumpu pada salah satu kaki (kaki poros) pada saat pemain tersebut menguasai bola. Adapun kaki yang dipindahkan dapat melewati depan atau melewati belakang. Gerakan pivot berguna untuk melindungi bola dari perebutan pemain lawan, untuk kemudian bola tersebut dioperkan kepada lawannya atau untuk mengadakan tembakan. Pemain yang jangkung yang dipasang di sekitar basket perlu sekali mahir untuk melakukan pivot untuk menembak.

\section{f. Teknik Rebound}

Rebound adalah suatu istilah dalam permainan bola basket dimana seorang pemain menangkap atau mendapatkan bola pantul yang tidak berhasil masuk yang ditembakkan oleh pemain lain. Pebasket yang melakukan rebound kebanyakan adalah yang berada diposisi center (tengah) dan power forward. Karena rebound lebih efektif untuk orang yang bertubuh lebih tinggi dan yang lebih dekat dengan ring basket.

g. Teknik footwork (olah kaki)

Dalam permainan bola basket membutuhkan footwork yang baik. Ada pemain yang memiliki kecepatan dan agility yang lebih baik daripada yang lain, kecepatan dan agility pemain akan sangat meningkat jika didukung oleh footwork yang baik. Pemain dengan kecepatan dan agility yang baik bisa saja dikalahkan dengan mudah oleh pemain yang memiliki footwork yang sempurna.

\section{h. Teknik Ball Handling}

Penguasaan bola pada saat memegang bola yang biasa disebut ball handling. Ball handling biasa terlihat pada saat melakukan teknik dasar dribbling.

\section{i. Teknik Take Position}

Posisi saat mendapatkan bola Take Position yaitu posisi tangan, kaki dan badan pada saat memegang bola menghadap kearah ring untuk dapat siap mengambil keputusan baik akan melakukan passing, dribbling maupun langsung finishing.

Dalam permainan bola basket banyak faktor yang menjadi penghambat pemain dalam mencetak angka, antara lain faktor keberhasilan lepas dari penjagaan. Hal-hal tersebut dapat menyebabkan pemain sulit mendapatkan angka dengan 
mudah dan sering membuat persentase bola yang tidak masuk lebih banyak dibandingkan dengan persentase bola masuk. Disinilah pentingnya sebuah screen offense agar lepas dari penjagaan lawan dan mendapatkan peluang menghasilkan point atau passing bagi sebuah tim bola basket.

Teknik screen adalah penting karena screen yang tidak efektif tidak berkontribusi pada pelanggaran dan benarbenar dapat mengurangi aliran offense melalui waktu dan gerakan yang terbuang dan pelanggaran yang tidak perlu. (Brown, 2009)

Screen adalah penting untuk jangka panjang efektifitas pelanggaran. Yang terbaik dari program basket selalu digunakan screen sebagai hal penting bagi mereka yang melakukan offense. (Brown, 2009)

Screen melibatkan 4 langkah yaitu :

1) Setting the screen,

2) Seing the screen,

3) Using the screen,

4) Freeing the screen. (Rose, 2013)

Screen adalah salah satu hal yang paling diabaikan, meskipun merupakan sesuatu yang dapat dijangkau yang hanya membutuhkan kerja dan konsentrasi. Pemain dapat belajar menjadi screen hood, terutama jika mereka tidak egois dan berorientasi tim, banyak jenis screen dalam bola basket. (Rose, 2013) Screen yang merupakan taktik dalam menyerang (offense) bagian dari strategi dalam memecahkan pertahanan (defense) untuk menghasilkan point. Screen untuk offense merupakan taktik dalam sebuah serangan yang sangat lumrah dilakukan oleh sebuah tim untuk memenangkan suatu pertandingan dalam melawan musuhnya atau tim lain.

Permainan bola basket merupakan kombinasi dari offense dan defense, untuk itu seorang pemain haruslah menguasai teknik dan keterampilan dasar dalam bermain basket. (Rose, 2013)

Ada delapan gerakan dasar dalam menyerang yang sebaiknya dikuasai:

1. Change of pace (mengubah kecepatan langkah)

2. Change of direction (mengubah arah)

3. One-two stop (satu dua berhenti)
4. Jump stop (melompat-berhenti)

5. Front turn (berputar maju)

6. Reverse turn (berputar kebelakang)

7. Two foot jump (melompat dengan dua kaki)

8. One foot jump (melompat dengan satu kaki).(Wissel, 2012)

Pada saat pertandingan pun taktik screen yang dilakukan berulangkali seringkali akan terpecahkan oleh lawan maka daripada itu perlu adanya evaluasi taktik screen jadi ketika sudah terbaca oleh lawan pelatih dapat menggantinya agar dapat lebih mudah membebaskan pemain dan menghasilkan point.

Apakah yang dapat membantu hal tersebut banyaknya evaluasi pada saat pertandingan dapat terlihat kekuatan atau kelemahan sebuah tim, taktik ataupun strategi yang diterapkan pada pertandingan.

Maka dari hal tersebut perlu dilakukan analisis screen pada sebuah pertandingan. Serta dapat menjadi referensi untuk para pelatih untuk mengetahui tingkat kegagalan dan keberhasilan screen offense dalam sebuah pertandingan.

\section{METODE}

Metode dalam penelitian ini termasuk dalam metode deskriptif dengan teknik pengambilan data observasi atau survei. Metode deskriptif adalah suatu metode yang digunakan untuk menggambarkan atau menganalisis suatu hasil penelitian tetapi tidak digunakan untuk membuat kesimpulan yang lebih luas.

Penelitian ini bermaksud mengetahui persentase tingkat keberhasilan screen offense pada tim putri Universitas Negeri Jakarta. Teknik dari penelitian ini adalah observasi dalam bentuk metode penilaian yaitu observasi dengan teknik dokumenter. Observasi dengan teknik dokumenter yaitu berupa melihat video pertandingan yang sudah ada di youtube dan mengambil serta menganalisa data-data tentang screen offense yang terjadi ditiap game dalam satu event.

Penelitian ini adalah 12 pemain tim bola basket putri Universitas Negeri Jakarta pada Liga Mahasiswa Basketball Prim-A Greater Jakarta Conference 2019. Teknik pengambilan sampel total sampling yaitu 
karena pada saat bertanding semua pemain melakukan screen offense maka sampel dalam penelitian ini adalah seluruh pemain basket putri Universitas Negeri Jakarta. Pengumpulan data menggunakan blanko keberhasilan dan kegagalan dengan kriteria screen offense sebagai berikut

- Berhasil karena mendapatkan passing, passing adalah mengumpan atau mengoper bola kearah teman satu tim.

- Berhasil karena adanya peluang shooting, shooting adalah usaha memasukkan bola ke dalam ring basket lawan untuk meraih point.

- Gagal karena tidak mendapatkan passing, tidak mendapatkan passing karena tidak adanya peluang untuk di passing.

- Gagal karena tidak ada peluang shooting, tidak ada peluang shooting karena tidak mendapatkan passing atau lawan sudah berada dijarak dekat.

\section{HASIL DAN PEMBAHASAN}

Persentase tingkat keberhasilan dan kegagalan screen offense Tim Bola Basket Putri Universitas Negeri Jakarta Pada Liga Mahasiswa Basketball PrimA Greater Jakarta Conference 2019.

Tabel 1. Keberhasilan dan kegagalan screen offense Tim Bola Basket Putri Universitas Negeri Jakarta

\begin{tabular}{ccccc}
\hline \multirow{2}{*}{ Ptd } & \multirow{2}{*}{ UNJ vs } & \multicolumn{2}{c}{ Screen Offense } & \multirow{2}{*}{$\sum$} \\
\cline { 3 - 4 } & & Berhasil & Gagal & \\
\hline 1 & UNTAR & 15 & 7 & 22 \\
\hline 2 & UEU & 11 & 13 & 24 \\
\hline 3 & UPRES & 28 & 14 & 42 \\
\hline 4 & UPH & 25 & 29 & 54 \\
\hline 5 & $\begin{array}{c}\text { PERBA } \\
\text { NA }\end{array}$ & 20 & 6 & 26 \\
\hline & $\sum$ & 99 & 69 & 168 \\
\hline
\end{tabular}

a. Dari data yang diperoleh dari jumlah keseluruhan aktivitas screen offense adalah sebagai berikut.

Tabel Data keseluruhan kemampuan screen offense Tim Bola Basket Putri Universitas Negeri Jakarta

\begin{tabular}{|cccccc} 
Screen Offense & B & G & $\sum$ & $\begin{array}{c}\% \\
\text { B }\end{array}$ & $\begin{array}{c}\% \\
\text { G }\end{array}$ \\
\hline Hasil & 99 & 69 & 168 & 59 & 41 \\
\hline
\end{tabular}

Dari data perhitungan diatas dapat diketahui bahwa tingkat keberhasilan screen offense lebih besar dibandingkan tingkat kegagalannya, yaitu tingkat keberhasilan 58,93\% (dibulatkan menjadi 59\%) dan tingkat kegagalan sebesar 41,07\% (dibulatkan menjadi $41 \%$ ). hal tersebut dapat dilihat dari diagram batang dibawah ini:

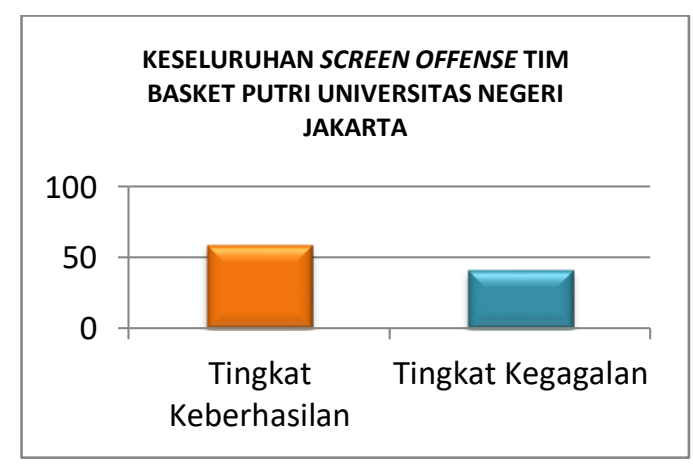

Gambar 1. Keseluruhan persentase tingkat keberhasilan dan kegagalan screen offense Tim Bola Basket Putri Universitas Negeri Jakarta.

\section{PEMBAHASAN}

Screen offense adalah sebuah usaha untuk membebaskan teman offense dari penjagaan lawan agar dapat menghasilkan point. screen offense juga merupakan taktik untuk menembus pertahanan lawan pada saat menyerang, unsur yang terpenting dalam mengetahui tingkat keberhasilan screen 
offense adalah dengan mendapatkan passing setelah terlepas dari penjagaan lawan pemain tersebut meminta passing kepada teman offense yang memegang bola, mendapatkan passing juga sangat penting karna ketika sudah melakukan screen offense tetapi tidak mendapatakan passing maka dapat dikatakan gagal dalam screen offense.

Dalam melakukan screen offense sangat penting terbangun kerjasama dan komunikasi yang baik antara pemain yang satu dengan pemain lainnya yang melakukan offense agar dapat terjadi gerakan screen yang efektif dan efisien. Selain mendapatkan passing mempunyai peluang shooting juga merupakan faktor keberhasilan screen karena tujuan utama dari screen offense merupakan mendapatkan peluang untuk mencetaka angka, ketika pemain sudah lolos dari penjagaan serta mendapatkan passing besar kemungkinan pemain tersebut mempunyai kesempatan shooting dan menghasilkan point.

Tabel 2 Kontribusi Screen Offense untuk point pada saat pertandingan Tim Bola Basket Putri Universitas Negeri Jakarta

\begin{tabular}{cccc}
\hline PTD & $\begin{array}{c}\text { Point } \\
\text { Seluruh } \\
\text { nya }\end{array}$ & $\begin{array}{c}\text { Kontri } \\
\text { busi } \\
\text { Screen } \\
\text { Untuk } \\
\text { Point }\end{array}$ & $\begin{array}{c}\text { Kontri } \\
\text { busi } \\
(\boldsymbol{\%})\end{array}$ \\
\hline UNTAR & 43 & 4 & $9,30 \%$ \\
\hline UEU & 31 & 4 & $12,90 \%$ \\
\hline UPRES & 56 & 11 & $19,64 \%$ \\
\hline UPH & 41 & 11 & $26,83 \%$ \\
\hline PERBA & 39 & 4 & $10,26 \%$ \\
NAS & & & \\
\hline$\sum$ & $\mathbf{2 1 0}$ & $\mathbf{3 4}$ & $\mathbf{1 6 , 1 9}$ \\
& & & $\mathbf{\%}$ \\
\hline
\end{tabular}

Dari data perhitungan diatas terdapat keseluruhan kontribusi screen offense untuk point dalam 5 pertandingan, yaitu yang pertama Universitas Negeri Jakarta melawan Universitas Tarumanegara dari 43 point keseluruhan screen offense berkontribusi 4 point jika dipersentasekan 9,30\%, pertandingan yang kedua melawan Universitas Esa Unggul dari 31 point keseluruhan screen offense berkontribusi 4 point jika di persentasekan $12,90 \%$, pertandingan yang ketiga melawan Universitas President dari 56 point keseluruhan screen offense berkontribusi 11 point jika dipersentasekan 19,64\%, pertandingan yang keempat melawan Universitas Pelita Harapan dari 41 point keseluruhan screen offense berkontribusi 11 point jika dipersentasekan $26,83 \%$ dan pertandingan yang kelima melawan Perbanas Institute dari 39 point keseluruhan screen offense berkontribusi 4 point jika dipersentasekan 10,26\%.

Keseluruhan point dari 5 pertandingan yaitu 210 point keseluruhan screen offense berkontribusi 34 point jika dipersentasekan 16,19\%, dari data tersebut dapat terlihat screen offense jika tingkat keberhasilan tim basket putri Universitas Negeri Jakarta dapat meningkat disetiap pertandingan maka banyak pula point yang akan dihasilkan di setiap pertandingan dan akan lebih besar untuk memenangkan pertandingan.

Berdasarkan hasil pengamatan dan hasil penelitian didapatkan bahwa tim basket putri Universitas Negeri Jakarta lebih besar persentase tingkat keberhasilan screen offense dibandingkan tingkat kegagalannya dikarenakan tim basket putri Universitas Negeri Jakarta banyak mendapatkan 
passing yaitu sebanyak 60 kali dan banyak pula peluang shooting yaitu 39 kali, hal tersebut disebabkan karena para pemain tim basket putri Universitas Negeri Jakarta banyak melakukan screen offense dan mereka melakukan screen dengan benar sehingga pemain defense tertahan dan pemain yang di screen terbebas dari penjagaan, pada saat sudah terbebas dari penjagaan para pemain cepat untuk mengambil keputusan shooting sehingga tingkat keberhasilannya untuk point pun cukup besar ini menunjukan screen offense sangat berguna dalam taktiik penyerangan karena dapat menghasilkan point.

Dalam seluruh pertandingan tim basket putri Universitas Negeri Jakarta sangat sering sekali melakukan screen offense untuk membebaskan teman dari penjagaan persentase keberhasilannya pun cukup besar dikarenakan pada event Liga Mahasiswa ini persiapan yang dilakukan sudah terbilang lama karena event ini menjadi target tim tiap tahunnya, dapat dilihat dari video pertandingan tim basket putri Universitas Negeri Jakarta dalam melakukan screen offense tingkat keberhasilannya mengikuti point dan lawannya, ketika lawannya kuat dalam defense maka kegagalan screen offense dalam pertandingan itu pun cukup besar dikarenakan lawan tidak tertahan oleh pemain yang melakukan screen dan lawan pun cepat keposisi penjagaannya kembali dalam artian lawan berhasil mengejar pemain offense yang sudah di screen dan mencegah pemain tersebut melakukan shooting, begitupun sebaliknya tim putri Universitas Negeri Jakarta ketika lawannya lemah dalam defense tingkat keberhasilan screen offense pun tinggi dikarenakan pemain lawan yang di screen menyangkut dan berhasil membebaskan pemain offense lainnya dari penjagaan serta pemain tersebutpun mendapatkan bola dan mendapatkan peluang shooting.

Keseluruhan point dari 5 pertandingan yaitu 210 point keseluruhan screen offense berkontribusi 34 point jika dipersentasekan 16.19\%, Dari 5 pertandingan diperoleh 99 kali screen offense berhasil yang menghasilkan persentase 59\% keberhasilan dan 69 kali screen offense gagal yang menghasilkan $41 \%$ kegagalan hal ini menunjukan tim basket putri Universitas Negeri Jakarta berhasil melakukan screen offense.

Secara keseluruhan 5 pertandingan dari hasil analisis screen offense pada video pertandingan diperoleh 99 kali screen offense berhasil yang menghasilkan persentase 59\% keberhasilan dan 69 kali screen offense gagal yang menghasilkan $41 \%$ kegagalan, keseluruhan point dari 5 pertandingan yaitu 210 point keseluruhan screen offense berkontribusi 34 point jika dipersentasekan $16.19 \%$, berikut hasil analisis SWOT dalam 5 pertandingan tersebut.

Kekuatan tim UNJ

1. Keseluruhan pemain dapat bermain Tim.

2. Banyaknya gerakan screen offense yang berhasil dapat menghambat pemain defense.

3. Banyaknya pemain yang melakukan finishing setelah terlepas dari penjagaan.

4. Terjalinnya komunikasi yang baik antar pemain dilapangan.

5. Dapat melakukan fast break

Kelemahan tim UNJ

1. Banyaknya miss comunikasi antar pemain pada saat melakukan screen offense.

2. Beberapa pemain masih memaksakan melakukan finishing ketika lawan masih defense dengan baik.

3. Tidak point ketika finishing. 
4. Beberapa pemain belum memahami tugasnya masing-masing sesuai posisinya.

5. Banyaknya Turn Over yang dilakukan. Peluang Tim UNJ

1. Dapat bermain sesuai dengan sistem.

2. Memperoleh angka dengan keberhasilan melakukan screen offense.

3. Banyaknya peluang finishing.

4. Dapat bermain dengan free style menerobos pertahanan lawan.

Ancaman Tim UNJ

1. Adanya intercept yang dilakukan lawan.

2. Kurang tepatnya timing dalam melakukan screen offense.

3. Lawan melakukan defense dengan kuat.

\section{KESIMPULAN}

Berdasarkan hasil penelitian tim basket putri Universitas Negeri Jakarta lebih besar persentase tingkat keberhasilan screen offense dibandingkan tingkat kegagalannya, dikarenakan tim basket putri Universitas Negeri Jakarta banyak mendapatkan passing yaitu sebanyak 60 kali dan banyak pula peluang shooting yaitu 39 kali. Perbandingan tingkat keberhasilan screen offense tim putri Universitas Negeri Jakarta dapat diketahui yaitu sebanyak (59\%) dan tingkat kegagalan sebanyak (41\%) hal ini menunjukan tim basket putri Universitas Negeri Jakarta berhasil melakukan screen offense.

\section{SARAN}

1. Perlu adanya pemahaman screen offense yang lebih mendalam untuk mengetahui tujuan utama dari screen tersebut.

2. Perlu dilakukan latihan screen offense untuk menghadapi pertandingan selanjutnya agar tingkat keberhasilan screen offense meningkat dan dapat menghasilkan point.

3. Perlu adanya komunikasi dan kerjasama tim yang baik untuk dapat melakukan keberhasilan screen offense antara pemain satu tim.
4. Pelatih perlu lebih cepat membaca situasi dalam pertandingan untuk dapat mengantisipasi dan menemukan solusi untuk pemecahan masalah atau kekurangan tim dalam satu pertandingan.

5. Selalu membuat analisis dan evaluasi dalam satu pertandingan untuk dapat menjadi masukan dan perbaikan untuk pertandingan selanjutnya.

\section{DAFTAR PUSTAKA}

Brown. Hubie, NBA Coaches Playbook, Human Kinetik, 2009.

Iman Sulaiman Coaching Basketball Fudamental Penataran Pelatih Tingkat Dasar, Jakarta: PB.PERBASl, 2019.

Iman Sulaiman, I., Fajrin, A. R., Studi, P., Kepelatihan, P., Olahraga, F. I., \& Timur, J. (2018). Offense Bola Basket. 09(01), 68-76.

Rose, Lee H. 2013. The Basketball Handbook. United States of America: Human Kinetics, 2013.

Suharsimi Arikunto. Prosedur Penelitian Suatu Pendekatan Praktek. Jakarta: PT. Rineka Cipta

Sudjana, Metode Statistika Bandung:Tarsito), 2005.

Wissel, Hal. Step To Succes Bola Basket. Jakarta: PT. Raja Grafindo Persada, 2012. 